Artigo original

\title{
Aspectos clínicos e anatomopatológicos da reparação de defeito osteocondral experimental da cabeça umeral de cães, após aplicação de laser a diodo de arsenieto de gálio
} Effects of gallium arsenate diode laser application
on articular cartilage experimental defect in dog umeral head

Cristina Boock de Souza Rodrigues, M.Sc.*, Ricardo Junqueira Del Carlo, D.Sc.**, Celber René Limonge**, Betânia de Souza Monteiro ${ }^{* * * *}$ Lisandra Cristina Perez Pinheiro*****, Antônio José Natali, D.Sc. ${ }^{* * * * *}$, Taise Domingues de Souza, M.Sc. ${ }^{* * * * * *}$

*Fisioterapeuta, Mestre em Medicina Veterinária, **Médico Veterinário, Pesquisador CNPq, Professor Titular, Orientador Programa de Pós-graduação em Medicina Veterinária da Universidade Federal de Viçosa (UFV), ***Fisioterapeuta, Especialista em osteopatia, mestrando em Medicina Veterinária (UFV), ${ }^{* * * *}$ Médica Veterinária, m estranda em Medicina Veterinária (UFV), *****Graduanda Medicina Veterinária (UFV), bolsista PIBIC/CNPq, ${ }^{* * * * *}$ Licenciado em Educação Física, Professor Adjunto (UFV), ******Médica Veterinária, Professora Assistente, Universidade de Vila Velha

\section{Resumo}

Foi avaliada, por meio de exames clínicos e anátomopatológicos, a influência do laser a diodo de arsenieto de gálio (As-Ga) na reparação articular da cabeça umeral de 36 cães após osteocondroplastia experimental. O laser determinou efeito analgésico logo após a sua aplicação, melhorou a deambulação após 21 dias e potencializou a reparação.

Palavras-chave: laserterapia, cartilagem articular, lesão osteocondral.

\begin{abstract}
The influence of Gallium-Arsenate (As-Ga) diode laser on the repairing process of dog humeral heads after experimental osteochondroplasty was assessed by clinical and anatomopathological examinations. The laser provided analgesic effect immediately after its application, improved lameness after 21 days and had a great repairing potential.
\end{abstract}

Key-words: laser therapy, articular cartilage, osteochondral defect.

\section{Introdução}

A cartilagem articular é uma estrutura complexa que absorve choque durante o movimento articular [1]. Sua nutrição deriva do líquido sinovial produzido pela membrana sinovial e, em menor grau, da difusão de substratos sanguíneos que cursam através do osso subcondral [2]. O líquido sinovial também é responsável pela lubrificação das superfícies deslizantes [1-3].

As lesôes superficiais da cartilagem articular, que não envolvem o osso subcondral, possuem pouca capacidade intrínseca de reparação, por se tratar de um tecido desprovido de irrigação sangüínea e, portanto, dependente da vascularizaçáo proveniente da medula óssea para que ocorra migração de células mesenquimais, responsáveis pelo processo de cicatrização [4-6].

Após lesôes, o tecido de reparação tende a se tornar cartilaginoso, mas permanece com características fibrosas, e sua natureza é biomecanicamente importante [7]. Mesmo quando histologicamente semelhante à cartilagem hialina, difere da cartilagem articular normal, bioquímica e biomecanicamente [8] e, freqüentemente, a longo prazo, são observadas extensas 
alteraçóes degenerativas, iniciando-se com fibrilação superficial da cartilagem de reparação e posterior formação de fissuras, ocorrendo ainda diminuição na celularidade e perda da afinidade tintorial pela safranina $\mathrm{O}$ [5].

Os efeitos fisioterápicos do laser de baixa potência estáo fundamentados na sua ação vasodilatadora pré-capilar e capilar, que melhora a circulação e aumenta a oxigenação, o aporte de nutrientes e a retirada de catabólitos. Também promove modificações na pressão hidrostática, favorecendo a reabsorção de edemas. Além disso, inibe a síntese de prostaglandinas, eleva o limiar da dor, estimula a produção de endorfinas, restabelece a homeostase celular e atua positivamente sobre a regeneração tecidual pela elevação do metabolismo [9].

O objetivo deste trabalho foi avaliar, por meio de exames clínicos e anátomopatológicos, a influência do laser a diodo de arsenieto de gálio (As-Ga) na reparação da cartilagem articular da cabeça umeral de cáes após osteocondroplastia experimental.

\section{Materiais e métodos}

Foram utilizados 32 cáes adultos, machos e fêmeas, clinicamente sadios, sem raça definida, pesando entre 10 e 20 $\mathrm{kg}$, provenientes do canil experimental do Departamento de Veterinária da Universidade Federal de Viçosa.

Após procedimentos rotineiros pré-operatórios e de anestesia geral, a articulaçáo escápulo-umeral esquerda de todos os cáes foi abordada, conforme estabelecido por Piermattei [10]. Após incisáo da cápsula articular, realizou-se a rotaçáo medial e extensão do membro, que resultou na exposição da porção caudal da cabeça do úmero. Com auxílio de um punch de biopsia circular de seis milímetros de diâmetro, foi delimitado um defeito na cartilagem articular. $\mathrm{O}$ tecido cartilaginoso circunscrito foi removido por meio de uma perfuratriz elétrica, na velocidade de 2000 rpm, sob irrigação contínua com solução ringer-lactato. A profundidade do defeito criado foi a espessura completa da cartilagem articular, até penetrar o osso subcondral, evidenciando sangramento. As bordas da lesão foram mantidas perpendiculares em relação à superfície articular e a articulação foi lavada com solução de ringer-lactato para remoçáo de pequenos fragmentos cartilaginosos. Em seguida, a cápsula articular e os planos cirúrgicos foram suturados.

Nas primeiras 24 horas após a intervenção cirúrgica a articulaçáo operada foi imobilizada por uma bandagem de Velpeau [11], e os animais mantidos em baias individuais. Posteriormente, os cães foram transferidos para canis coletivos (quatro cães/canil), recebendo ração comercial (Biriba - Guabi S/A) e água à vontade. Os animais foram medicados com enrofloxacina (Duotril 10\% - Duprat) $(10 \mathrm{mg} / \mathrm{kg} /$ s.c. a cada 24 horas), imediatamente antes e durante cinco dias após a cirurgia, e cetoprofeno (Profenid injetável - Aventis) (1,1 $\mathrm{mg} / \mathrm{kg} / \mathrm{s}$.c. a cada 24 horas) por três dias, após a cirurgia.

Os 32 cáes foram distribuídos aleatoriamente em dois grupos experimentais. Os 16 cães do Grupo controle (GC) foram separados em quatro subgrupos de quatro animais (C1, C2, C3 e C4), submetidos somente ao procedimento cirúrgico e avaliados antes da cirurgia e durante sete, 21, 35 e 60 dias após a cirurgia, respectivamente. Os 16 cães do Grupo tratado (GT) também foram separados em quatro subgrupos de quatro animais (T1, T2, T3 e T4), e submetidos ao procedimento cirúrgico, porém neste grupo foi realizada aplicação do laser As-Ga. A primeira aplicação foi feita no primeiro dia de pós-operatório e as seguintes sempre com intervalo de 48 horas, até atingirem sete, 21, 35 e 60 dias, de acordo com o subgrupo experimental, submetidos a três, sete, 12 e 20 sessóes, respectivamente.

As aplicaçôes de laser As-Ga foram realizadas com um aparelho (Laser Infra-Red 904 - KLD, Biossistemas Equipamentos Eletrônicos Ltda) de $45 \mathrm{~W}$ (watts) de potência máxima e comprimento de onda de $904 \mathrm{~nm}$, na dose de 4 $\mathrm{J} / \mathrm{cm}^{2}$ por ponto. $\mathrm{O}$ animal foi colocado em decúbito lateral direito e após a identificação do acrômio esquerdo, o membro torácico esquerdo foi estendido e rotacionado medialmente ficando paralelo à coluna vertebral. Um ponto cranial, outro caudal e o último ventral em relaçáo ao acrômio foram irradiados em cada animal, com a extremidade da caneta do laser, em contato com a pele, posicionada de modo a incidir perpendicularmente ao defeito.

Clinicamente os animais foram avaliados quanto a presença ou ausência de claudicação e pressão de apoio dos membros operados. Para análise da claudicação, foram submetidos a caminhadas diárias, sendo que no grupo tratado a avaliação foi feita antes e após a aplicação do laser.

A mensuração da pressáo de apoio do membro torácico esquerdo foi realizada uma vez antes do procedimento cirúrgico e diariamente após a cirurgia nos animais dos grupos controle e tratado, utilizando uma balança de precisão digital e um tablado de madeira de altura igual ao do piso da balança. $\mathrm{O}$ procedimento foi realizado por um único observador.

Ao atingir o período para avaliação previsto para cada subgrupo (sete, 21, 35 ou 60 dias), os animais de GC e GT foram sacrificados. A articulação escápulo-umeral operada foi dissecada e avaliada macroscopicamente, quanto à conformaçáo e ao aspecto do preenchimento do defeito.

A análise estatística foi feita por meio de análise de variância da regressão (para avaliação da pressão de apoio dos membros de GC e GT) e o teste $t$ foi feito para avaliar a pressão de apoio antes e após a aplicação do laser. Foi adotado o nível de significância de até 5\%. A avaliação de claudicação foi descritiva.

\section{Resultados e discussão}

$\mathrm{Na}$ avaliação clínica do GT, todos os animais apresentaram durante a primeira sessão de aplicação do laser (primeiro dia pós-operatório), a área operada edemaciada e dolorosa à manipulação. Todavia 48 horas após a cirurgia (durante a segunda sessão), os animais permitiram a manipulação do 
membro operado. Resultados similares a esses também foram observados no GC nos primeiros dias pós-operatórios.

No quesito claudicação, foi observado que os animais do C1 e T1 comportaram-se de forma semelhante. Enquanto, os animais dos subgrupos T2, T3 e T4, comparados com o subgrupo controle respectivo, apoiaram mais precocemente o membro operado. Resultados similares foram descritos por Lobato [1], ao assegurar que o laser, clinicamente, diminuiu os sinais inflamatórios e a dor, permitindo melhor desempenho e maior amplitude de movimento.

Pela análise de variância da regressão, verificou-se uma relação funcional entre a recuperação dos animais, medida pela variação na pressão de apoio e o tempo de tratamento pós-operatório. Tal relação aplicou-se tanto para o grupo tratado como para o controle (Figuras 1 e 2).

Figura 1 - Gráfico de regressão do indice de pressão, medido em porcentagem, em função dos dias decorridos após a cirurgia, para o subgrupo $C 4$.

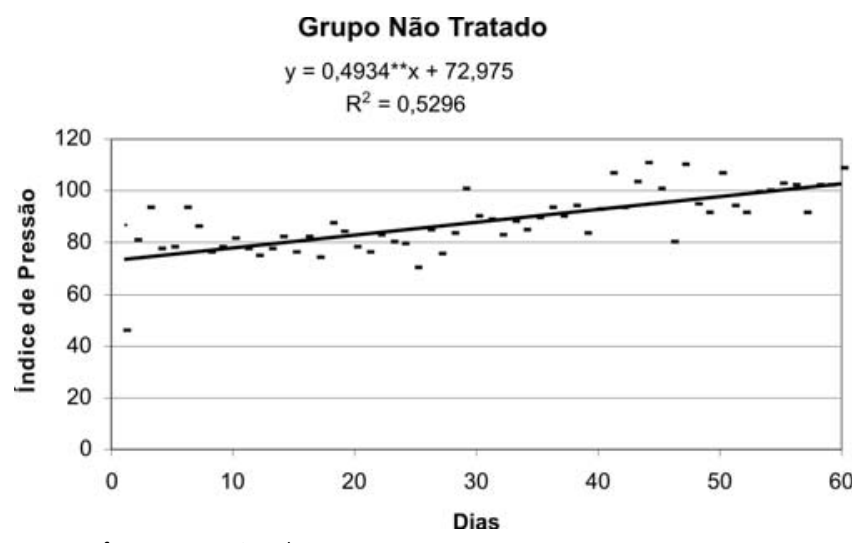

** significativo a $1 \%$ pelo teste $t$.

Figura 2 - Gráfico da regressão do indice de pressão, medido em porcentagem, em função dos dias decorridos após a cirurgia, para o subgrupo T4.

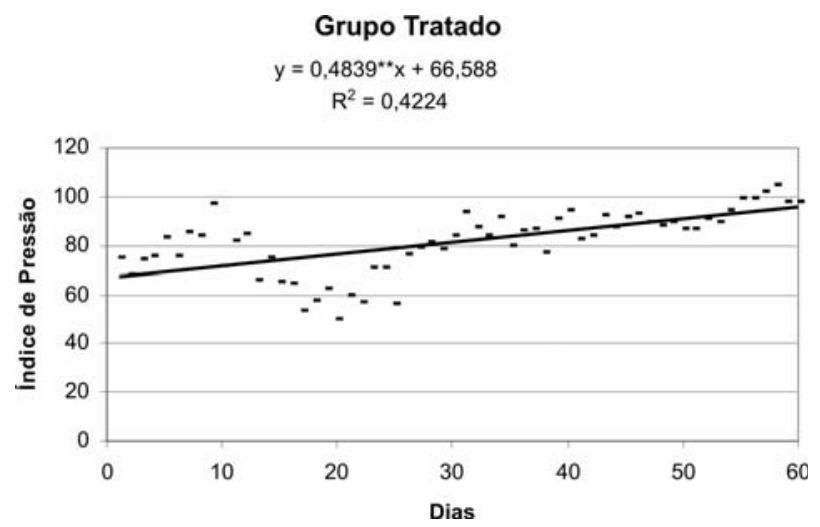

** significativo a $1 \%$ pelo teste $t$.
Embora tenha havido significância para a regressão nos dois grupos, os coeficientes de determinação apresentaram-se baixos, o que indica baixa adequabilidade do linear simples para aquelas situaçóes ou, ainda, um ajuste inadequado em apenas parte do tempo em que os animais foram expostos à recuperação.

Esperava-se uma taxa de recuperação maior, ao longo do tempo, para o grupo tratado, devido ao efeito analgésico do laser [12], mas foi verificado que os modelos lineares ajustados para ambos os grupos foram estatisticamente idênticos. Tal afirmação foi verificada pela significância do coeficiente de correlação (R) entre os resíduos resultantes das duas equações, o que indicou que esses modelos proporcionaram desvios iguais para cada ponto considerado da variável tempo. Isto foi aplicado para todos os subgrupos controle e tratado. Pode-se inferir também que o método de avaliação, balança de precisão e tablado, não permitiu a avaliação precisa da pressão de apoio, que variava em funçáo de movimentos do animal, como abanar da cauda, posiçáo da cabeça dentre outros.

O teste " $t$ " para dados pareados demonstrou, em média, que a pressão de apoio após a aplicação do laser foi maior do que a medida imediatamente antes, caracterizando efeito analgésico imediatamente após a laserterapia, conforme demonstrado em coelhos por Burr [1] e Piermattei e Flo [13].

A análise macroscópica realizada após o sacrifício mostrou melhor preenchimento do defeito nos animais do GT, comparados com o GC, ao longo do tempo (Figura 3).

$\mathrm{O}$ defeito dos animais $\mathrm{C} 1 \mathrm{e} \mathrm{T} 1$, aos sete dias, permaneceu com as bordas definidas e regulares, com o fundo preenchido por material de coloraçáo vermelho escuro, semelhante a coágulo sangüíneo.

Nos animais do C2, aos 21 dias, o tecido de reparação que preenchia o defeito apresentou coloração rósea-avermelhada e as bordas mantiveram-se definidas. No T2, as bordas do defeito apresentaram-se irregulares e arredondadas e o preenchimento foi uniforme, porém sem atingir a superfície articular e o tecido de reparação assumiu coloraçáo esbranquiçada a rósea.

Nos animais do C3, aos 35 dias, os defeitos apresentavamse com as bordas irregulares e arredondadas. $\mathrm{O}$ preenchimento do defeito aconteceu de forma incompleta, com tecido de reparação amarelado a róseo. No T3 as bordas do defeito estavam arredondadas, com preenchimento até as proximidades da superfície articular, por um tecido de coloração róseo-esbraquiçado.

Nos animais do C4, aos 60 dias, o preenchimento da falha não alcançou o nível da superfície da cartilagem articular normal, as bordas da lesão mantiveram-se irregulares e o tecido de reparação tinha coloração esbranquiçada a rósea, com alguns pontos amarelados. No T4, em três animais, as bordas permaneceram arredondadas, a falha estava preenchida por tecido de coloração esbranquiçada a rósea até a proximidade da superfície articular. Em um animal o preenchimento da falha foi total e se deu por tecido semelhante a cartilagem. 
Os resultados foram semelhantes aos obtidos por Souza [14] que observou, em falhas osteocondrais no joelho de coelhos, preenchimento parcial após duas semanas, evoluindo para preenchimento completo as quatro e sete semanas após o procedimento cirúrgico, na maioria dos animais. Por outro lado, Hurtig et al. [4] observaram pequena reparação um mês após a criação de falhas osteocondrais em eqüinos. Mas, após quatro meses, observaram um tecido róseo recobrindo o fundo, porém sem preenchimento até o nível da superfície articular, o que aconteceu somente aos 9 meses. Esses achados indicam que o processo de reparação de falhas osteocondrais pode variar de espécie para espécie, podendo também ser influenciado pelo tamanho, formato e localização do defeito. Também existe variação individual, conforme observado em um animal do T4, cujo preenchimento do defeito atingiu o nível da superfície articular.

Figura 3 - Aspecto macroscópico da falha osteocondral da cabeça do úmero de cães sacrificados nos diferentes tempos pós-operatórios (PO). C1 (7 dias), preenchimento da falha com coágulo. T1 (7 dias), material de preenchimento semelhante ao C1. C2 (21 dias), defeito preenchida com tecido de coloração rósea-avermelhada. T2 (21 dias), melhor preenchimento do que C2. C3 (35 dias), preenchimento ainda incompleto com tecido amarelado a róseo. T3 (35 dias) preenchimento incompleto por tecido de reparação esbranquiçado a róseo. C4 (60 dias), preenchimento incompleto por tecido de reparação esbranquiçado a róseo. T4 (60 dias), tecido semelhante à cartilagem remanescente preenchendo o defeito.

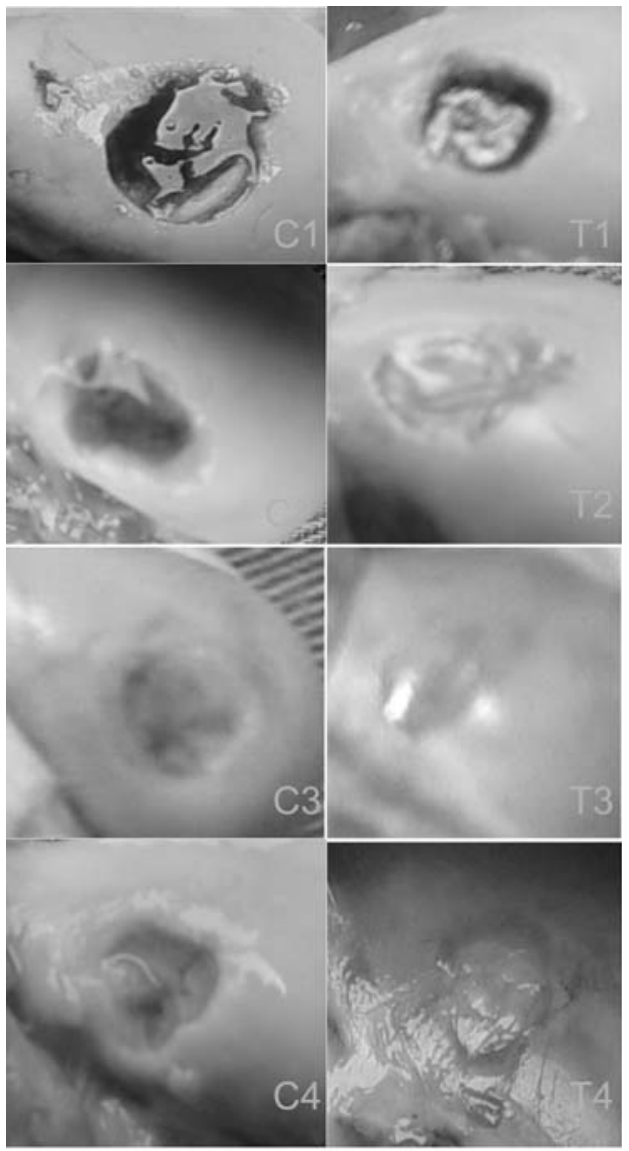

\section{Conclusão}

Com base nos resultados do presente estudo, conclui-se que o laser a diodo de arsenieto de gálio aplicado após osteocondroplastia da cabeça do úmero, em cáes, apresentou efeito analgésico logo após a sua aplicação; melhorou deambulação após 21 dias e potencializou a reparação do defeito.

\section{Referências}

1. Burr DB. Anatomy and physiology of the mineralized tissues: role in the pathogenesis of osteoarthrosis. Osteoart and Cartil 2004;1-11.

2. Cambell CJ. The healing of cartilage defects. Clin Orthop Relat Res 1969;64:45-63.

3. Hettinga DL. Resposta inflamatória das estruturas sinoviais da articulação In: Gould JA. Fisioterapia na ortopedia e na medicina do esporte. 2 ed. São Paulo: Manole; 1993. p.87-117.

4. Hurtig MB, Fretz PB, Doige CE et al. Effects of lesion size and location on equine articular cartilage repair. Can J Vet Res 1998;52(1):137-46.

5. Kettunen K. Effect of articular function on the repair of a fullthickness defects of the joint cartilage. An experimental study of mature rats. Ann Chir Gynaec 1963;52:627-42.

6. Lamas MCS. Laser a diodo de arsenieto de gálio (As-Ga) aplicado às fraturas do terço médio do rádio de cães. [dissertação]. Belo Horizonte MG: Escola de Veterinária da UFMG; 1999. 49p.

7. Lammi PE, Lammi MJ, Tammi RH et al. Strong hyaluronam expression in the full-thickness rat articular cartilage repair tissue. Histoch Cell Biol 2001;115(4):301-8.

8. Lobato DA. Efeitos da aplicação do laser a diodo de Arsenieto de Gálio (As-Ga) na osteoartrite experimental em coelhos. [dissertação]. Viçosa MG: Departamento de Veterinária da UFV; 2003. 29p.

9. Luger EJ, Wollman Y, Rochkind SD et al. The effect of low level laser irradiation on bone cell culture. Laser Therapy 1998;10:558.

10. Navratil L, Dylevsky I. Mechanisms of the analgesic effect of the therapeutic lasers in vivo. Laser Therapy 1997;9:33-40.

11. Ortiz MCS. Efeito do laser de baixa potência sobre o processo inflamatório articular de coelhos. [dissertação]. São Paulo SP: Departamento de Fisioterapia da UFSCar; 2001. 161p.

12. Piermattei DL. An atlas of surgical approaches to the bones and joints of the dog and cat. 3 ed. Philadelphia: Saunders; 1993. $324 \mathrm{p}$.

13. Piermattei DL. Flo GL Manual de ortopedia e tratamento das fraturas dos pequenos animais. 3 ed. São Paulo: Manole; 1999. $694 \mathrm{p}$.

14. Souza TD. Efeitos da eletroestimulação no processo da reparação de falhas osteocondrais em coelhos. Estudo experimental. [dissertação]. Viçosa MG: Departamento de Veterinária da UFV; 1998. $51 \mathrm{p}$. 